\title{
A Dialectical Approach to Positive Organizational Studies*
}

\author{
Miguel Pereira Lopes \\ School of Social and Political Sciences, Technical University of Lisbon, Rua Almerindo Lessa, Lisboa, Portugal. \\ Email: mplopes@iscsp.utl.pt
}

Received November $9^{\text {th }}, 2012$; revised December $17^{\text {th }}, 2012$; accepted January $18^{\text {th }}, 2013$

Copyright (c) 2013 Miguel Pereira Lopes. This is an open access article distributed under the Creative Commons Attribution License, which permits unrestricted use, distribution, and reproduction in any medium, provided the original work is properly cited.

\begin{abstract}
Over the last decade, an academic movement emerged towards the study of positive phenomena in management and organization studies. Since then, two different scientific research streams have emerged in line with this positive approach to management: 1) positive organizational scholarship (POS), which proposes a trait approach view of positive virtues and strengths and sees the environment as a moderator variable which facilitates or not the exhibition of corresponding positive behaviours; and positive organizational behaviour (POB), which defends a state-like perspective of positive characteristics, thus putting a strong emphasis on situational factors as determinants of positive behaviour, leaving a marginal role to positive psychological traits. As a critical comparison between these two different research streams is yet to be done, in this paper I propose a dialectical approach to study positivity in organizations and contrast these two different ontological approaches to positivity in organizations. I presented arguments to demonstrate that each of these approaches alone constitute quite a limited proposal in that each of them seems to misleadingly assume that: traits cannot be changed; they show incongruence between assumptions and purpose and; they constitute biased viewpoints. A dialectical approach makes possible to overcome these shortcomings by assuming both personality characteristics and environmental features relate each other in an intertwined complex way to produce positive behaviour in organizations. I finally present some practical implications that a dialectical approach would have to organizations and managers.
\end{abstract}

Keywords: Positive Organizational Scholarship; Positive Organizational Behaviour; Dialectical Approach; Personality Traits; Psychological States; Positive Organizations

\section{Introduction}

Over the last decade, an academic movement emerged towards the study of positive phenomena in peoples' life [1-3]. By positive phenomena the movement proponents meant those things that made life worth living, through the promotion of growth, learning, self-development, and the attainment of positive states like exhilaration, enthusiasm, stamina or flow. A stronger interest in many scholars rose up and a large set of positive constructs have come to capture business and management academics' attention. The quick spread of positive construct analysis seemed to be accentuated as the positive movement extended to the organizational field. Subjects like gratitude, resilience, positive emotions, optimism, energizing relationships, or happiness, just to name but a few, have been targeted and studied by management scholars [4].

\footnotetext{
*A previous version of this paper was presented at the 2005 Annual Meeting of the European Academy of Management (EURAM) in München, Germany.
}

As this movement unfolded, two different approaches rose from the study of positive behaviour in organizations: positive organizational scholarship (POS) and positive organizational behaviour (POB). In the present article, I argue that these two approaches differ at first in their ontological stances. Ontology refers to the assumptions about primitive elements or components of reality and describes the facts to be considered in scientific analysis, specifying what exists [5]. It is about theories of the fundamental nature of the world and human functioning [6]. While POB advocates that positive behaviour characteristics should be seen firstly as a consequence of positive psychological states $[7,8]$, POS defends that these behaviours result from more stable and consistent psychological traits, like positive virtues [9] or character strengths [10]. As such, POS and POB represent separate ontological assumptions since they point different reality components as the core elements to explain positive behaviour. Though many scholars now call themselves interactionists, I agree with Pervin [11] in that they still 
disagree about whether the person or the situation is the one which should be emphasized. This is the case for most POS and POB researchers.

The goal of this article is this to propose a dialectical interactionist perspective to positive organizational studies that overcomes the antagonistic approaches of POS and POB. I do not aim to review the literature in POS and POB, nor do I present a critical review of each of the approaches ${ }^{1}$. I argue instead that POS and POB contain, in its extreme forms, antithetic ontological assumptions that may be integrated within a dialectical frame of analysis. I also discuss some advantages of adopting a dialectical approach to the study of positivity in organizations.

With this in mind I structured the present paper by outlining each approach's assumptions, making the case for a dichotomy argument. After, I discuss three shortcomings of both POS and POB and, as a consequence, propose a dialectical perspective of positive behaviour in organizational settings. I then discuss the implications of adopting such an integrative view in terms of its conceptual, methodological and applied aspects.

\section{Positive Organizational Scholarship}

Positive Organizational Scholarship (POS) is "a new movement in organizational science that focuses on the dynamics leading to exceptional individual and organizational performance such as developing human strength, producing resilience and restoration, and fostering vitality" [12]. Leading our understanding of positive dynamoics and outcomes in organizations, POS has proven its virtuousness through many aspects. First, it was original in introducing new territories within the organizational field, opening a large new scientific domain in which we can explore and raise our understanding of organizational functioning. Rooted in the pioneering movement from the University of Michigan Business School, and one of the twenty breakthrough Harvard Business Review's ideas for 2004, POS did not reject the importance of studying dysfunctional dynamics within organizations, but stressed the need of considering the ennobling aspects of human life $[3,13]$. Second, POS has assured the respect that any scientific approach requires. It advocates a bias toward scholarship which is based firstly in following the scientific method and on following methods rooted in a "careful definition of terms, a rationale for prescriptions and recommendations, consistency with scientific procedures in drawing conclusions, and groun-

\footnotetext{
${ }^{1}$ For further information on the POS aims and research findings, please refer to M. P. Lopes, M. P., Cunha, S. Kaiser and G. Muller-Seitz, "Positive Organizational Scholarship: Embodying a Humanistic Perspective on Business," In: H. Spitzeck, W. Amann, M. Pirson, S. Khan and E. Kimakowitz, Eds., Humanism in Business: State of the Art, Cambridge University Press, Cambridge, 2009, pp. 278-298.
}

ding in previous related work" [2]. This bias is rooted in positive psychology $[1,14]$. Third, the large amount of theories developed under the umbrella of POS have favoured a rich theoretical diversity allowing the inclusion of individual, relational, and situational factors as explanatory elements of positive behaviour [15-17].

However, individual trait-like factors have assumed prevalence. In the words of known authors of positive psychology movement such as Aspinwall and Staudinger [18], "Many efforts to understand and identify human strengths have focused on the individual-level traitsintelligence, optimism, self-efficacy, ego resilience-associated with good life outcomes" (p. 12). This does not mean that these theories are the only existing in the POS approach since "POS does not represent a single theory" [2]. It only reports the fact that trait-like POS theories are the more salient within these organizational scholars, both because they are directly rooted in the trait tradition of positive psychology [19], and because important researchers in the foundation of POS tended to favour such a view of the positive phenomena, considering "the study of positive individual traits" as the major topic for research [14].

This trait-like bias is also evident from the enabling character some POS theories attribute to organizational context. According to them, POS should emphasize "the examination of factors that enable positive consequences for individuals, groups, and organizations" [2]. As these enablers require the existence of some latent strength or virtue already existing but not being exhibited, some authors have considered more or less explicitly that people already have positive personality traits which may or may not become behaviourally expressed if the organizational context "enables" its exhibition [20]. This leads directly to a trait ontological perspective that attributes a moderator role to the situational variables of organizational context, and contrast with the POB approach to positivity in organizations.

\section{Positive Organizational Behavior}

Some authors, namely Fred Luthans, have developed a distinct view of what could be a positive approach to organizations [7,8,21,22]. Luthans [8] firstly defined POB as "the study and application of positively oriented human resource strengths and psychological capacities that can be measured, developed, and effectively managed for performance improvement in today's workplace” (p. 59). POB is a derivative of the positive psychology movement since more than seeing employees as a means to attain organizational productivity, the $\mathrm{POB}$ approach calls for the pursuit of employee happiness, health, and personal betterment as an end in itself [21].

Asserting that POB strives to understand how we can develop positive psychological capacities and strengths 
and consequentially assuming that they can be developed, one must necessarily accept the potentially state-like character of the POB constructs and "rule out the more fixed, trait-like personality, attitudinal, and motivational variables traditionally associated with OB” [8].

Some positive characteristics fall down the requisites to be considered in the POB approach (i.e. measurable, developable and manageable). Luthans [8] includes confidence (self-efficacy), hope, optimism, subjective wellbeing or happiness, and emotional intelligence in that group of positive characteristics, with self-efficacy opening $[14,23,24]$.

The state-like bias assumed in the POB approach looks somewhat at odds with the core assumptions of positive psychology movement's models and proposals. As Luthans [22] put it, POB "includes state-like concepts rather than the dispositional, trait-like taxonomy of character or virtues called for in positive psychology” (p. 698). In the opposite of POS, researchers framed on POB support a state-like ontological nature of positivity. In this way, they attribute a different status to organizational context. Instead of a moderator role as in POS, situational variables are seen as responsible for the trigger of positive psychological states and thus important ontological elements.

POB also differs from POS in that while this tends to emphasise the positive organizational characteristics that enhance organizational survival and effectiveness in times of crises and adverse conditions, POB "applies positively-oriented human strengths and psychological capacities that can be measured, developed and managed for performance improvement $(\cdots)$ through workplace interventions and proactive management" [7]. Thus, we may consider that positive psychology has spurred two related movements in management and organization studies - two different twins - that applied positivity and strengths based management to the workplace: POS and POB.

Like the POS movement, POB has become important to the advancement of positive management for at least two reasons. First, it calls the attention both to the benefits of applying positive principles in the workplace. Second, it stresses the need to increase our understanding of how to improve positive behaviour in organizational settings. Authentic leadership, for instance, provide stronger insight about how to promote positive outcomes through a workforce [25]. Authentic leadership, for instance, is "a process that draws from both positive psychological capacities and a highly developed organizational context, which results in both greater self-regulated positive behaviour on the part of leaders and associates, fostering positive self-development" [26]. Research has evidenced that a leader's support of this kind leads to positive outcomes both for employees (job satis- faction, positive mood) and for organizations (commitment, reductions in withdrawal behaviour, performance) [27].

\section{Shortcomings of POS and POB}

In this section, I argue that both POS and POB face important shortcomings. I discuss here three major shortcomings affecting equally the two approaches: 1) they tend to assume that traits are immutable or even innate which is dubiously supported by current literature; 2) they show incongruence between their assumptions and their purpose; and 3) they represent unbalanced approaches, favouring either a situationist (psychological states) or a personalistic (psychological traits) view of positivity.

\subsection{Immutability of Traits}

Authors from both POS and POB approaches tend to assume that traits are immutable or even innate. Although some trait defenders would certainly down on that thesis, many scholar would disagree. Steyer, Krambeer and Hannöver [28], for instance, have argued that although trait scores should not be affected by the present situation (by definition), traits still probably are subject to change between occasions of measurement due to learning or critical events the individual undergoes. Eid [29] also argues that some examples of trait change "are alterations in attitudes or traits due to learning, therapeutic interventions, development, etc.” (p. 148). Furthermore, there is empirical evidence that traits do change as a result of specific treatments. Elder and Clip [30], for example, found positive changes in personality characteristics from adolescence to midlife following exposure to the extreme life event of heavy war combat. After war combat, veterans were more goal-oriented, assertive and less helpless than they were during adolescence. We have thus evidence to believe that traits do change and are not fixed entities.

Instead of a materialistic view of traits, we can look at them as behavioural regularities that help us to explain the behaviour, and thus traits must not be necessarily seen as neither innate, nor unchangeable [31]. This is a similar perspective as that of Mischel who came to view traits as conditional probabilities that a particular action will be evoked [32]. Considering traits as behavioural consistency has even made possible to attribute personality traits to non-human animals [33]. What we argue is that these behavioural regularities might change over time mainly as a result of meaningful life experiences and personal learning [34]. Although some might say that this is the evidence that traits do not exist or are not important in predicting and promoting behaviour we would immediately reply that their criticism is due to their con- 
ceptions of what a trait is. All in all, we should not discard the conception of traits as changeable under certain conditions.

Although it is sometimes argued that traits and states are arbitrary and even unnecessary labels [35], research has shown that states and traits have strong and inextricable relations. As Allen and Potkay [35] put it, "To assume states (variable behaviour) is also to assume its opposite, traits (constant behaviour)” (p. 925). In fact, empirical research relying on the Spielberger's STAI (State-Trait Anxiety Inventory), for instance, has demonstrated that "the common latent trait variable of repeatedly measured anxiety states was strongly correlated with the common latent trait variable of the repeatedly administered trait scale" [34], which supports the assumption that, although states can be measured, there is always a latent trait with the necessary power to explain behaveioural variance. In fact, the idea that traits influence psychological states is an established one [36].

This reflects a shortcoming to both POS and POB approaches. For POB scholars, the implication is that they have ignored the role of traits in developing positivity. Failing to recognize the changing nature of traits has taken POB authors to deny their existence or importance. This is an important limitation since POB must explain positive behavioural consistencies that occur in different, sometimes antithetic, situations? For POS researchers, assuming a fixed nature of human traits have meant a divorce from a developmental proactive perspective that was probably in the origins of the need for a POB approach. As such, for both positive organizational approaches, not to accept the changing nature of positive individual traits has come to represent an important limitation.

\subsection{Incongruence between Assumptions and Purpose}

Both POS and POB also show from within, an incongruence between assumptions and purpose. If POS scholars defend a fixed trait-approach (assumption), they should reject the possibility to promote any positivity besides that which comes from environmental enablement. Even the word "promote" seems, in a certain way, at odds with the idea that everything that organizations can do is to enable positivity. This does not seem to be the case, since some POS authors are determined to understand how to promote positivity (purpose) [37].

A similar incongruence is seen in the POB approach. To explain it, we must go first through a definition of the concepts of trait and state. Allport and Odbert [38] were pioneering in defining these two constructs. Traits were defined as "Consistent and stable modes of an individual's adjustment to his environment", whereas states were considered "Present activity, temporary states of mind and mood” (p. 26). Traits are thus stable, longlasting and internally caused. States are temporary, brief, and caused by external circumstances [39]. So assuming that the POB proponents defend within a state-like frame that its purpose is to "measure, develop, and effectively manage for performance improvement”, we might always ask, "to develop" what? Can states be developed? Does this make sense? Accepting and following these well established state and trait conceptual definitions one must conclude there is, in fact, an incongruence within the POB approach, which advocates a state-like perspective (assumption) for the one hand, but presents positive development as a core goal (purpose), for the other.

It is always possible try to explain this incongruence by asserting that developing positivity in a POB perspective only confines to promoting the behavioural and state-type ephemeral occurrence of positive behaviours (i.e. increasing positive behaviour frequency), but that is doubtful and less useful. Doubtful, because POB proponents have sometimes advocated a lifespan perspective of positive development (cf. Luthans \& Avolio [26]). Less useful, because these behavioural and state-like positive occurrences would not in itself provide an ensuring, consistent and long-range positive development in behaviour.

\subsection{Unbalanced Character}

A third shortcoming of both POB and POS is that they represent unbalanced approaches, favouring situations or personality traits as major determinants of positive behaviour. When defining POS and in line with positive psychology, authors have focused primarily in individual (positive subjective experiences and positive individual traits) than on the context [20]. Though stressing the importance of the organizational context as an influencing variable, POS has given little attention to the study of that contexts' key features such as organizational culture, structures, processes, leadership [2,40], thus presenting an unbalanced approach as a whole towards the individual.

In the other way, POB favours a strong situationist perspective. The creation of temporary states of mind and temporary moods is many times attributed to situational constraints only. POB authors have thus applied a situationist approach to explain and instil desired behaviours. In trouble to explain why is it that different persons behave differently within the same environmental features (what would challenge them to accept a trait perspective), situationists justified that fact with the past history of contingencies that each individual has undergone [31]. However, this is a justification for individual regular behaviour, what accordingly to our definition would be a justification for traits (that have been developed through the lifespan). 
We must admit that, as Bowers [31] affirms, "Traits are inventions and there is no reason for believing that they should account for all the available person variance" (p. 325). But that shouldn't take us to remark that situations can explain all the behaviour. We would better adopt an interactionist perspective. People are active situation seekers, they don't just fall down on situations as experimental subjects do [31,41]. And so, we should not minimize the role that traits play in peoples' life. Furthermore, an interactionist perspective advocates that situations are construed in everyday life experiences. This life experiences or psychological states are certainly important, both in the way people structure reality and how they change their personal traits in the course of their life. Instead of a "state or trait" standpoint we should probably go further to a "state and trait" position. We should thus search for a comprehensive model of positivity improvement in organizations. I turn to this issue right now.

\section{An Integrative Dialectical Approach}

A model biased towards traits would see situational variables as moderators of the trait-behaviour relations (Figure 1(a)) [20,42]. A bias towards situations would perspective psychological states as moderator variables of the situation-behaviour relations (Figure 1(b)). This last one is the case of those who studied psychological constructs as self-monitoring [43] or personal consistency [44]. A "true" integrative model would not see any of the two - either traits/states or situations - only as moderators, but instead the behaviour as the result of multiple direct and indirect relations between traits/states and situations. It would thus assume that behaviour results from a multiple net of relations between traits and situational features [45].

Latent state-trait theory (LST theory) proposed recently by Stayer [28,34] provides a good example of an unbiased interactionist perspective. LST theory aims to take into account the fact that situations and the interaction between them are also important sources of variance in psychological measurement. This, of course, allows us to consider simultaneously the presence of traits, situations and psychological states and, as such, to supersede the dichotomy between the situationism of POS and the personalism of POB. In the words of Steyer et al. [28], "LST theory, in our mind, is best suited to reflect the concepts of traits and states, and relate them to the dis- tinctions between persons and situations”. In light of LST theory, traits characterize "persons" whereas states characterize "persons-in-situations".

In consequence, the models embedded in LST theory are suitable both for measuring persons-in-situations and for estimating the degree of both trait and situational influences. In addition, latent variables theory and the multivariate models its application entangles [46,47], make possible to detect and measure real trait changes and not only ephemeral state changes. Trait changes are the most important for developmentalists since they try to instil long-range enduring behavioural modifications in abilities or attitudes.

LST theory relies on the idea that given an observable variable (e.g. a test-score, psychological or other measurement) it can be decomposed into a latent state variable and an error measurement variable (Figure 2). Latent state variable might be decomposed into a latent trait variable and an occasion-specific residual. Measurement error variables represent the part of observable random variables not determined by the person, by the situation, or by the interaction between person and situation. Occasion-specific residual should reflect, in its turn, situational and/or interactional effects between traits and situations.

As such, LST theory integrates in a comprehensive intertwined interactionist fashion the situation, the trait and the state components so often taken as separable in psychological and organizational theory. It constitutes a "pure" interactionist approach since it views neither traits nor situations as moderator variables, but as equal determinants of psychological states and behaviour.

(a)

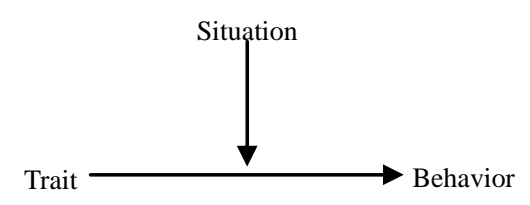

(b)

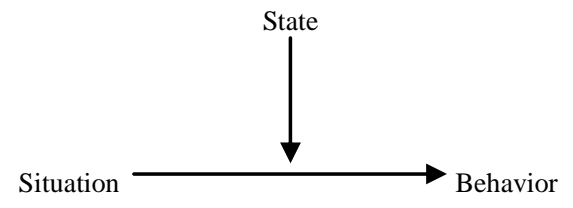

Figure 1. Role of traits and situations in (a) POS and (b) POB.

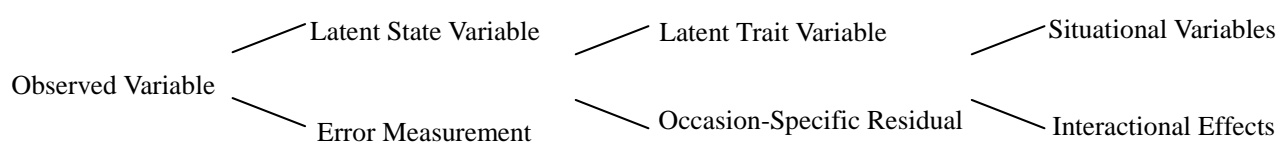

Figure 2. Components of latent state-trait theory. 
Conceptually, this means we should look to the relation between traits and situations as a dialectic one. Dialectical approaches are judged to be appropriate to theory development. Specifically, the use of paradoxical thinking as a way to depict dialectical processes should serve our purpose to analyse the antithetical relation between POS and POB. Paradoxes allow theorists to study the dialectics between opposing levels and forces held by different theories.

For our discussion I consider the paradoxical relation between POS ontological nature of positive behaviour transpiring a bias towards traits (thesis), and POB ontology claiming situational primacy through the promotion of positive psychological states (antithesis). An integrative dialectical approach of organizational positivity would be able to supersede this theoretical tension by the development of a middle range theory (synthesis), positing the mutual existence of both (Figure 3).

I argue that an integrative dialectical approach would bring important conceptual, methodological and practical implications for the study of positive behaviour in organizations. I develop now each of these implications.

\subsection{Conceptual Implications}

By proposing an integrative dialectical model we believe we are contributing to the theoretical advancement of positive organization science by proposing a comprehensive integrative model that considers psychological traits, psychological states and situational factors as important elements to explain positivity in organizations. We follow the scholarly scientific vein that POS movement proponents' have preached as a necessary element to make respectable and reliable a new research field, relying our analysis in established theory.

A major implication of a dialectical interactionist model for positive organizing is the ontological integration of the dual nature of human social behaviour. The ontological nature of human agency (implicit in trait models of personality) and social structure (implicit in situationist models) haslong been the focus of deep scientific discussion in sociological [48], anthropological [49], and psychological fields [50]. Authors have come to conclude that a dialectical approach was necessary to cut the action-structure antithetic opposition and situate human agency within the social structure.

A dialectical approach to human positive behaviour

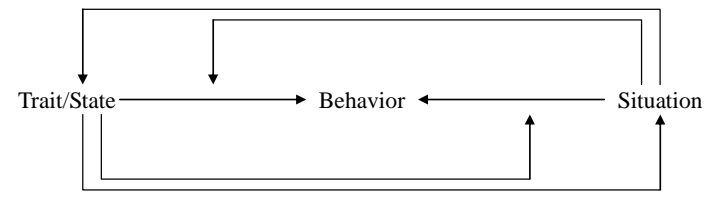

Figure 3. Multiple roles of traits and situations in a dialectic approach. accepts that the social structure plays a major role in determining positive psychological states as much as POB does. But it also recognizes that social structures are the result of human action [48]. While one can conceptualize personal agency as a mindful epiphenomenon of deterministic situational forces, an interactionist approach would postulate that people can exert some deliberate influence over their life by choosing the environments they get in or even by building them [50]. This is in accordance with the POS reliance on personal consistency (psychological traits) throughout different situations.

Proposing a dialectical approach to positive behaviour in organizational settings means to assert that human action is always a product of both the present pressures and the embodied history internalized in durable individual structures, the habitus in Bourdieu's [49] theory of practice. As such, both situational variables promoting positive psychological states (as stressed by the POB approach) and psychological trait variables (as emphasized by the POS approach) play an important role to explain positive behaviour, avoiding the need to rule out any of them. In light of this, agent and structure may be seen as a monism [51].

Positive organizational researchers thus, should no longer ignore the agentic positive psychological trait, or the structural situational environment of positive behaviour. We should always keep in mind that both personal dispositions and environmental features play an inextricable role in understanding positive phenomena. This would imply that both in theory and research, we should not assume an unbalanced viewpoint.

\subsection{Methodological Implications}

An integrative dialectical approach to positivity in organizations also requires some methodological and measurement fundamental cautions. First, it calls for the need to measure not only psychological states and traits, as has been the case for most research in the field (e.g. hope as a state and hope as a trait; [52,53], but also situational factors as determinants of positive behaviour. Few studies have assessed environmental characteristics in the positive organizational behaviour equation. Cameron, Dutton, Quinn and Wrzesniewski [40] have considered measurement issues in organizational positivity an "unanswered question". The study conducted by Cameron, Bright and Caza [54] is a quite singular example. Examining the relation between virtuousness and organizational results, the authors developed a measure of virtuous organizational climates, which constitutes one of the few measures in positive organization studies not assessing individual characteristics. Although some theoretical models propose situational variables as relevant to explain positive behaviour (e.g. the authentic leadership development model; [26]), research has been scarce or 
null in demonstrating empirical evidence for such environmental effects.

Rasmussen et al. [55] pointed three main reasons for why environmental assessment is underdeveloped in positive studies. First, environmental contexts are difficult to contextualize. Second, there is an "ideology of individualism" focusing on "the persons as the responseble agent of behavior". Third, the context is wrongly perceived as fixed or too difficult to change and thus its study is "fruitless". Adopting an integrative dialectical view of positive behavior one would assert, however, the imperative to measure organizational contexts in positive management research. In fact, environmental and job characteristics have been pointed as promoters of positive behavioral change $[7,25]$, but empirical evidence is yet to come. In the same vein, organizational level variables such as human resource management practices and organizational culture are also unstudied in positive organization studies.

A dialectical integrative approach would also imply a shift in the methodological design of research in positive organization studies. This is partly because a dialectical perspective gives primacy to a study level that not overestimates either individual traits (micro-level) or the organizational context (macro-level). The meso-level analysis has long been noticed by theorists as underrepresented in organization studies [56,57]. Positive organization studies should thus frame their research on a meso-level paradigm. This is not to say that there are not already middle-range theories in positive studies, especially in the POS approach. The work of Dutton [58] (see also Baker, Cross \& Wooten [59]) in high-quality connections and energizing relationships is an example. I buttress that these kinds of studies are the most fruitful and the one matching a dialectical integrative approach.

Several authors have called for different methodological assumptions as a way to take into account a mesolevel approach. Barley and Kunda [60] have argued that organizations need to "bring work back in", meaning that in order to study the links between macro-organizational changes and micro-organizational processes researchers need to go to the "ground". This would call for a resurgence of qualitative studies, such as interviews, content analysis and observation. Particularly, observational techniques are mainly important. As Barley and Kunda [60] put it "contemporary qualitative researchers tend to rely more heavily on interviewing and content analysis than observation. Although useful for studying points of view and meaning, such techniques are less adequate for studying work because most work practices are so contextualized that people often cannot articulate how they do what they do, unless they are in the process of doing it” (p. 81). Ethnographic studies may thus represent a better methodology to study the person in context, since on a dialectical basis "reality" does not directly affect behavior but is instead a construction of individuals as they make sense of a situation [61].

Methodological issues also call attention to the large amount of work needed to understand human behavior in organizational settings. How can we relate organizational "objective" characteristics with positive psychological states? How can we promote the development of positive psychological traits in and by organizations? How do people's characteristics influence the way they construe their environment in terms of it virtues? These are yet unanswered questions which might be drawn from a dialectical perspective and a middle-level methodological paradigm of positive behavior.

\subsection{Practical Implications}

Both POS and POB have come to propose a relatively wide array of routes to improve positivity in organizations. Improving positivity means increasing the frequency and magnitude of positive behaviours. Authors have acknowledged the possibility of changing the perceived positive organizational characteristics by changing the objective characteristics in place within the organization. For instance, by providing resources and active mastery experiences (objective characteristics), as proposed by Luthans and Youssef [7], the organization is supposed to alter peoples' perceptions about those characteristics. Those characteristics should lead to changes in positive individual states that would ultimately be reflected in some positive behavioural manifestation. Others also admitted that individual traits can be changed by training or other cognitive learning strategies or by some sort of "therapeutic" counselling or coaching [28,29,34]. A good amount of research also tried to demonstrate that organizational-level characteristics may directly influence the emergence of positive individual states, such as autonomy and a broad freedom of choice [62], environmental clarity [63], role clarity [64], or organizational culture [26], to name a few.

A dialectical approach to positive behaviour in organizations would look with caution to those proposals. If positive behaviour results from a dialectical construction involving both personality and environment, it may not be guaranteed that simply altering objective organizational characteristics, positive individual states will emerge. This is because there is an important interaction between positive traits and organizational characteristics. For example, Scheier, Carver \& Bridges [65] have demonstrated that optimists and pessimists may "see" a same "objective" world in quite different ways. In their words, "Optimists differ from pessimists in their stable coping tendencies $(\cdots)$ and in the kinds of coping responses that they spontaneously generate when given hypothetical 
coping situations” [65]: (p.1063). A challenge for a person may be another's worst nightmare.

The same goes for interventions focused on individual change, such as "positive training programs", "positive personal coaching" and other kind of personal change strategy. One should not expect that these personal strategies let alone would reveal more effective than situational-based strategies. Although its impact on the perceived positivity of organizational characteristics might be considerable, the "objective" organizational characteristics can impose their supremacy in the long run and make near null the impact of trait modification. This does not mean that an increase in positive states and in positive behaviour does not follow after those interventions, but that these effects cannot be considered apart from the environment.

As such, I do not deny that specific situations and contexts do influence the emergence of positive psychological states. What one must realize, however, is the superficial and limited impact that those positive states can have on organizational functioning. Ryan and Deci [66] have recently called the attention for the differential contrasting nature of hedonic and eudaemonic well-being. Hedonism reflect the view that well-being consists of direct, usually immediate, pleasure or happiness one can feel from attaining personal goals or expectations. Eudaemonic well-being argues that well-being comes from the fulfilling of basic psychological needs (autonomy, competence and relatedness) and the self-actualizing process. Hedonic and eudaemonic perspectives of positivity are empirical differentiated constructs [67].

This second approach-eudaemonic — is much more in accordance with what a dialectic perspective would sustain, for it is the personal meaning and purpose (construed as a mix of "person in context") that assures long-range positivity in organizations $[68,69]$. In the opposite, hedonism may bring a few more than the timelylimited "feeling good" of a positive state. For the practice of management this may mean that there is no easy route or prescription to improve positivity in organizations. Long-range positivity is certainly dependent on how people make sense of their work environment [70]. Organizations must capture what best can serve as a way for people to create meaning in what they do.

Meaning is a subjective kind of sense that people make of their work [71]. A dialectical approach to positivity advocates that people need to interpret what they do at work with a deep purpose. The work of Wrzersniewski and colleagues [72] illustrates quite well a dialectical tenet, when they state that " $\cdots$ what constitutes the experience of work - one that is not predetermined by individual attributes or the design of the job, but instead is open to the ways in which people shape their jobs to fit their own unique orientation toward the domain of work"
[71] (p. 300). Organizations need to create the necessary space to allow people "craft" their jobs in ways that are consistent with their orientations toward work.

This is not to say that organizations and managers cannot do anything to help people find meaning in what they are doing. As sense making tends to be socially construed [70], managers should manage meaning-making in units for which they have accountability by influencing how people interpret their jobs, organizations and communities. Meaningfulness occurs when goals, purpose and values are clarified and connected to the core values of employees [40]. Addressing how organizations can help employees' foster meaning, Pratt and Ashforth [73] distinguished between meaningfulness in work (related to work role) and meaningfulness at work (associated with group identity). They argue that meaning comes both from enriching the tasks one does and the membership characteristics one has, towards a state they call transcendent. Though managers and organizations can not prescribe the kind of job and identity membership characteristics each individual should be faced with, Pratt and Ashforth [73] propose that organizational practices such as recruitment and selection processes and socialization practices may be more or less tailored to foster each person's meaningfulness. They state that organizations should take more care with both the person-job fit and the person-organization fit if they are to create the conditions for a person to construe meaning within work. Given the impact of meaningfulness on employees' attitudes, motivation, performance and well-being, it may constitute one of the keystones of a dialectical approach to positive organizing.

In sum, this article aimed to present a dialectical approach to study positive behaviour in organizations. I believe dialectical thinking would constitute a theoretical, methodological and applied advancement to the maturing field of positive organizational studies. I hope it will stimulate further developments based on more integrative perspectives on this field of management research.

\section{REFERENCES}

[1] C. Peterson, "Positive Social Science," The Annals of the American Academy of Political and Social Science, Vol. 591, No.1, 2004, pp. 186-201. doi: $10.1177 / 0002716203260100$

[2] K. Cameron, J. Dutton and R. Quinn, "Foundations of Positive Organizational Scholarship,” In: K. S. Cameron, J. E. Dutton and R. E. Quinn, Eds., Positive Organizational Scholarship: Foundations of a New Discipline, Berrett-Koeller, San Francisco, 2003, pp. 3-13.

[3] M. Seligman and M. Csikszentmihalyi, "Positive Psychology: An Introduction," American Psychologist, Vol. 55, No. 1, 2000, pp. 5-14.

doi:10.1037/0003-066X.55.1.5 
[4] K. Cameron, J. Dutton and R. Quinn, "Positive Organizational Scholarship: Foundations of a New Discipline,” Berrett-Koeller, San Francisco, 2003.

[5] I. I. Mitroff and R. O. Mason, "Business Policy and Metaphysics: Some Philosophical Considerations,” Academy of Management Review, Vol. 7, No. 3, 1982, pp. 361-371.

[6] M. N. Chaninand and H. J. Shapiro, "Dialectical Inquiry in Strategic Planning: Extending the Boundaries," Academy of Management Review, Vol. 10, No. 4, 1985, pp. 663-675.

[7] F. Luthans and C. Youssef, "Human, Social, and Now Positive Psychological Capital Management: Investing in People for Competitive Advantage,” Organizational Dynamics, Vol. 33, No. 2, 2004, pp. 143-160. doi:10.1016/j.orgdyn.2004.01.003

[8] F. Luthans, "Positive Organizational Behavior: Developing and Managing Psychological Stregths,” Academy of Management Executive, Vol. 16, No. 1, 2002, pp. 57-72. doi:10.5465/AME.2002.6640181

[9] K. Cameron, "Organizational Virtuousness and Performance,” In: K. S. Cameron, J. E. Dutton and R. E. Quinn, Eds., Positive Organizational Scholarship: Foundations of a New Discipline, Berrett-Koeller, San Francisco, 2003, pp. 48-65.

[10] D. O. Clifton and J. K. Harter, "Investing in Strengths," In: K. S. Cameron, J. E. Dutton and R. E. Quinn, Eds., Positive Organizational Scholarship: Foundations of a New Discipline, Berrett-Koeller, San Francisco, 2003, pp. 111-121.

[11] L. A. Pervin, "Persons, Situations, Interactions: The History of a Controversy and a Discussion of Theoretical Models," Academy of Management Review, Vol. 14, No. 3, 1989, pp. 350-360.

[12] K. Cameron and A. Caza, "Contributions to the Discipline of Positive Organizational Scholarship,” American Behavioral Scientist, Vol. 47, No. 6, 2004, pp. 731-739. doi:10.1177/0002764203260207

[13] K. Cameron, D. Bright and A. Caza, "Exploring the Relationships between Organizational Virtuousness and Performance," American Behavioral Scientist, Vol. 47, No. 6, 2004, pp. 766-790. doi:10.1177/0002764203260209

[14] C. Petersonand and M. Seligman, "Positive Organizational Studies: Lessons from Positive Psychology,” In: K. S. Cameron, J. E. Dutton and R. E. Quinn, Eds., Positive Organizational Scholarship: Foundations of a New Discipline, Berrett-Koeller, San Francisco, 2003, pp. 14-27.

[15] G. Spreitzer and S. Sonenshein, "Positive Deviance and Extraordinary Organizing,” In: K. S. Cameron, J. E. Dutton and R. E. Quinn, Eds., Positive Organizational Scholarship: Foundations of a New Discipline, Berrett-Koeller, San Francisco, 2003, pp. 207-224.

[16] K. M. Sutcliffe and T. J. Vogus, "Organizing for Resilience,” In: K. S. Cameron, J. E. Dutton and R. E. Quinn, Eds., Positive Organizational Scholarship: Foundations of a New Discipline, Berrett-Koeller, San Francisco, 2003, pp. 94-110.

[17] A. S. Masten and M. J. Reed, "Resilience in Develop- ment,” In: C. R. Snyder and S. J. Lopez, Eds., Handbook of Positive Psychology, Oxford University Press, Oxford, 2002, pp. 74-88.

[18] L. G. Aspinwall and U. M. Staudinger, “A Psychology of Human Strenghts: Some Central Issues of an Emerging Field,” In: L. G. Aspinwall and U. M. Staudinger, Eds., A Psychology of Human Strengths: Fundamental Questions and Future Directions for a Positive Psychology, American Psychological Association, Washington DC, 2003, pp. 9-22. doi:10.1037/10566-001

[19] M. Seligman, "Forward: The Past and Future of Positive Psychology,” In: C. Keyes and J. Haidt, Eds., Flourishing: Positive Psychology and the Life Well-Lived, America Psychological Association, Washington DC, 2003, pp. 11-20.

[20] N. Park and C. Paterson, "Virtues and Organizations," In: K. S. Cameron, J. E. Dutton and R. E. Quinn, Eds., Positive Organizational Scholarship: Foundations of a New Discipline, Berrett-Koeller, San Francisco, 2003, pp. 3347.

[21] T. Wright, "Positive Organizational Behaviour: An Idea Whose Time Has Truly Come,” Journal of Organizational Behavior, Vol. 24, No. 4, 2003, pp. 437-442. doi:10.1002/job.197

[22] F. Luthans, “The Need for and Meaning of Positive Organizational Behaviour," Journal of Organizational Behavior, Vol. 23, No. 6, 2002, pp. 695-706. doi:10.1002/job.165

[23] A. Bandura, "Self-Efficacy,” In: V. S. Ramachaudran, Ed., Encyclopedia of Human Behaviour, Academic Press, New York, 1994, pp. 71-81.

[24] A. Stajkovicand and F. Luthans, "Social Cognitive Theory and Self-Efficacy: Going beyond Traditional Motivational and Behavioral Approaches,” Organizational Dynamics, Vol. 26, No. 4, 1998, pp. 62-74. doi:10.1016/S0090-2616(98)90006-7

[25] G. P. Hollenbeck and D. T. Hall, "Self-Confidence and Leader Performance,” Organizational Dynamics, Vol. 33, No. 3, 2004, pp. 254-269. doi:10.1016/j.orgdyn.2004.06.003

[26] F. Luthans and B. Avolio, "Authentic Leadership Development,” In: K. S. Cameron, J. E. Dutton and R. E. Quinn, Eds., Positive Organizational Scholarship: Foundations of a New Discipline, Berrett-Koeller, San Francisco, 2003, pp. 241-258.

[27] W. L. Gardner and J. R. Schermerhorn, "Unleashing Individual Potential: Performance Gains through Positive Organizational Behavior and Authentic Leadership,” Organizational Dynamics, Vol. 33, No. 3, 2004, pp. 270281.

[28] R. Steyer, S. Krambeer and W. Hannöver, "Modelling Latent Trait-Change,” In: K. Van Montfort, H. Oud and A. Satorra, Eds., Recent Developments in Structural Equation Modelling: Theory and Applications, Kluwer Academic Press, Amsterdam, 2004.

[29] M. Eid, "Happiness and Satisfaction: An Application of a Latent State-Trait Model for Ordinal Variables,” In: J. Rost and R. Langeheine, Eds., Applications of Latent 
Trait and Latent Class Models in the Social Sciences, Waxmann, Münster, 1997, pp. 145-151.

[30] G. E. Elder and E. C. Clipp, "Combat Experience and Emotional Health: Impairment and Resilience in Later Life," Journal of Personality, Vol. 57, No. 2, 1989, pp. 311-341. doi:10.1111/j.1467-6494.1989.tb00485.x

[31] K. S. Bowers, "Situationism in Psychology: An Analysis and A Critique,” Psychological Review, Vol. 80, No. 5, 1973, pp. 307-336. doi:10.1037/h0035592

[32] J. C. Wright and W. Mischel, “A Conditional Approach to Dispositional Constructs: The Local Predictability of Social Behaviour," Journal of Personality and Social Psychology, Vol. 53, No. 6, 1987, pp. 1159-1177. doi:10.1037/0022-3514.53.6.1159

[33] S. D. Gosling, V. S. Y. Kwan and O. P. John, “A Dog’s Got Personality: A Cross-Species Comparative Approach to Personality Judgments in Dogs and Humans,” Journal of Personality and Social Psychology, Vol. 85, No. 6, 2003, pp. 1161-1169. doi:10.1037/0022-3514.85.6.1161

[34] R. Steyer, M. Schmitt and M. Eid, "Latent State-Trait Theory and Research in Personality and Individual Differences," European Journal of Personality, Vol. 13, No. 5, 1999, pp. 389-408. doi:10.1002/(SICI)1099-0984(199909/10)13:5<389::AID -PER361>3.0.CO;2-A

[35] B. P. Allen and C. R. Potkay, "On the Arbitrary Distinctions between States and Traits,” Journal of Personality and Social Psychology, Vol. 41, No. 5, 1981, pp. 916-928. doi:10.1037/0022-3514.41.5.916

[36] T. W. Britt, K. A. Boniecki, T. K. Vescio, M. Biernat and L. M. Brown, "Intergroup Anxiety: A Person X Situation Approach,” Personality and Social Psychological Bulletin, Vol. 22, No. 11, 1996, pp. 1177-1188. doi:10.1177/01461672962211008

[37] D. L. Cooperrider and L. E. Sekerka, “Toward a Theory of Positive Organizational Change,” In: K. S. Cameron, J. E. Dutton and R. E. Quinn, Eds., Positive Organizational Scholarship: Foundations of a New Discipline, BerrettKoeller, San Francisco, 2003, pp. 225-240.

[38] G. W. Allportand and H. S. Odbert, "Trait Names: A Psycho-Lexical Study,” Psychological Monographs, Vol. 47, No. 1, 1936, p. i171.

[39] W. F. Chaplin, O. P. John and L. R. Goldberg, "Conceptions of States and Traits: Dimensional Attributes with Ideals as Prototypes," Journal of Personality and Social Psychology, Vol. 54, No. 4, 1988, pp. 541-557. doi:10.1037/0022-3514.54.4.541

[40] K. Cameron, J. Dutton, R. Quinn and A. Wrzesniewski, "Developing a Discipline of Positive Organizational Scholarship,” In: K. S. Cameron, J. E. Dutton and R. E. Quinn, Eds., Positive Organizational Scholarship: Foundations of a New Discipline, Berrett-Koeller, San Francisco, 2003, pp. 361-370.

[41] A. Bandura, "Social Cognitive Theory: An Agentic Perspective,” Annual Review of Psychology, Vol. 52, No. 1, 2001, pp. 1-26. doi:10.1146/annurev.psych.52.1.1

[42] L. K. Trevino, "Ethical Decision Making in Organizations: A Person-Situation Interactionist Model," Academy of
Management Review, Vol. 11, No. 3, 1986, pp. 601-617.

[43] M. Snyder, “Self-Monitoring Processes," Advances in Experimental Social Psychology, Vol. 12, 1979, pp. 85-128. doi:10.1016/S0065-2601(08)60260-9

[44] D. J. Bem and A. Allan, "On Predicting Some of the People Some of the Time,” Psychological Review, Vol. 81, No. 6, 1974, pp. 506-520. doi:10.1037/h0037130

[45] L. A. Kirkpatrick, "Effects of Multiple Determinacy and Measurement Error on Trait-Behavior and BehaviourBehavior Relations: An Integrated Conceptual Model," Personality and Social Psychological Bulletin, Vol. 23, No. 2, 1997, pp. 199-209. doi:10.1177/0146167297232008

[46] D. J. Ozer and S. P. Reise, "Personality Assessment," Annual Review of Psychology, Vol. 45, No. 1, 1994, pp. 357388. doi:10.1146/annurev.ps.45.020194.002041

[47] J. S. Wigginsand and A. L. Pincus, "Personality: Structure and Assessment,” Annual Review of Psychology, Vol. 43, 1992, pp. 473-504. doi:10.1146/annurev.ps.43.020192.002353

[48] A. Giddens, “The Constitution of Society,” Polity Press, Cambridge, UK, 1984.

[49] P. Bourdieu, "The Logic of Practice,” Polity Press, Cambridge, 1990.

[50] A. Bandura, "Human Agency in Social Cognitive Theory,” American Psychologist, Vol. 44, No. 9, 1989, pp. 1175-1184. doi:10.1037/0003-066X.44.9.1175

[51] B. Barnes, "The Macro/Micro Problem and the Problem of Structure and Agency," In: G. Ritzer and B. Smart, Eds., Handbook of Social Theory, Sage, London, 2001, pp. 339-352. doi:10.4135/9781848608351.n26

[52] C. R. Snyder, C. Harris, J. R. A. Anderson, S. A. Holleran, L. M. Irving, S. T. Sigmon, L. Yoshinobu, J. Gibb, C. Langelle and P. Harney, "The Will and the Ways: Development and Validation of an Individual-Differences Measure of Hope," Journal of Personality and Social Psychology, Vol. 60, No. 4, 1991, pp. 570-585. doi:10.1037/0022-3514.60.4.570

[53] C. Snyder, S. Sympson, F. Ybasco, T. Borders, M. Babyak and R. Higgins, "Development and Validation of the State Hope Scale," Journal of Personality and Social Psychology, Vol. 70, No. 2, 1996, pp. 321-335. doi:10.1037/0022-3514.70.2.321

[54] K. S. Cameron, D. Bright and A. Caza, "Exploring the Relationships between Organizational Virtuousness and Performance," American Behavioral Scientist, Vol. 47, No. 6, 2004, pp. 766-790. doi:10.1177/0002764203260209

[55] H. M. Rasmussen, J. E. Neufeld, J. C. Bouwkamp, L. M. Edwards, A. Ito, J. L. Magyar-Moe, J. A. Ryder and S. J. Lopez, "Environmental Assessment: Examining Influences on Optimal Human Functioning,” In: S. J. Lopez and C. R. Snyder, Eds., Positive Psychological Assessment: A Handbook of Models and Measures, American Psychological Association, Washington DC, 2003, pp. 443458. doi:10.1037/10612-028

[56] P. Cappelli and P. D. Scherer, "The Missing Role of Context in OB: The Need for a Meso-Level Approach," 
Research in Organizational Behavior, Vol. 13, 1991, pp. 55-110.

[57] D. M. Rousseau, "Issues of Level in Organizational Research,” Research in Organizational Behavior, Vol. 7, No. 1, 1985, pp. 1-38.

[58] J. Dutton, "Energize Your Workplace: How to Create and sustain High-Quality Connections at Work,” Jossey-Bass, San Francisco, 2003.

[59] W. Baker, R. Cross and M. Wooten, "Positive Organizational Network Analysis and Energizing Relationships," In: K. S. Cameron, J. E. Dutton and R. E. Quinn, Eds., Positive Organizational Scholarship: Foundations of a New Discipline, Berrett-Koeller, San Francisco, 2003, pp. 328-342.

[60] S. Barley and G. Kunda, "Bringing Work Back in,” Organization Science, Vol. 12, No. 1, 2001, pp. 76-95.

[61] G. Morgan, and L. Smircich, "The Case for Qualitative Research,” Academy of Management Review, Vol. 5, No. 4, 1980, pp. 491-500.

[62] L. Gratton, "Living Strategy: Putting People in the Heart of Corporate Purpose,” Prentice Hall, London, 2000.

[63] E. Lawler III, "Treat People Right: How Organizations and Individuals Can Propel Each Other into a Virtual Spiral of Success,” Jossey-Bass, San Francisco, 2003.

[64] N. Turner, J. Barling and A. Zacharatos, "Positive Psychology at Work,” In: C. R. Snyder and S. J. Lopez, Eds., Handbook of Positive Psychology, Oxford University Press, New York, 2002, pp. 715-728.

[65] M. F. Scheier, C. S. Carver and M. W. Bridges, "Distinguishing Optimism from Neuroticism (and Trait Anxiety, Self-Mastery, and Self-Esteem): A Reevaluation of the Life Orientation Test,” Journal of Personality and Social Psychology, Vol. 67, No. 6, 1994, pp. 1063-1078. doi:10.1037/0022-3514.67.6.1063

[66] R. M. Ryan and E. L. Deci, “On Happiness and Human
Potentials: A Review of Research on Hedonic and Eudaimonic Well-Being," Annual Review of Psychology, Vol. 52, No. 1, 2001, pp. 141-166. doi:10.1146/annurev.psych.52.1.141

[67] I. McGregor and B. R. Little, "Personal Projects, Happiness, and Meaning: On Doing Well and Being Yourself," Journal of Personality and Social Psychology, Vol. 74, No. 2, 1998, pp. 494-512. doi:10.1037/0022-3514.74.2.494

[68] C. L. M. Keyes and J. L. Magyar-Moe, “The Measurement and Utility of Adult Subjective Well-Being,” In: S. J. Lopez and C. R. Snyder, Eds., Positive Psychological Assessment: A Handbook of Models and Measures, American Psychological Association, Washington DC, 2003, pp. 411-526. doi:10.1037/10612-026

[69] C. D. Ryffand and C. L. M. Keyes, "The Structure of Psychological Well-Being Revisited,” Journal of Personality and Social Psychology, Vol. 69, No. 4, 1995, pp. 719-727. doi:10.1037/0022-3514.69.4.719

[70] K. E. Weick, "Sensemaking in Organizations," Sage, Thousand Oaks, 1995.

[71] A. Wrzersniewski, "Finding Positive Meaning in Work," In: K. S. Cameron, J. E. Dutton and R. E. Quinn, Eds., Positive Organizational Scholarship: Foundations of a New Discipline, Berrett-Koeller, San Francisco, 2003, pp. 296-308.

[72] A. Wrzersniewski and J. E. Dutton, "Crafting a Job: Revisioning Employees as Active Crafters of Their Work," Academy of Management Review, Vol. 26, No. 2, 2001, pp. 179-201.

[73] M. G. Pratt and B. E. Ashforth, "Fostering Meaningfulness in Working and at Work,” In: K. S. Cameron, J. E. Dutton and R. E. Quinn, Eds., Positive Organizational Scholarship: Foundations of a New Discipline, BerrettKoeller, San Francisco, 2003, pp. 309-327. 